\title{
A TRIBUTAÇÃO VERDE E A POSSIBILIDADE DE DISTORÇÕES VIOLADORAS DOS PRINCÍPIOS DA ISONOMIA E LIVRE CONCORRÊNCIA
}

\author{
Emília Aguiar Fonseca da Mota ${ }^{1}$ \\ Elisberg Francisco Bessa Lima²
}

\section{RESUMO}

O objetivo do estudo foi discutir a possível violação da tributação verde aos princípios da isonomia e livre concorrência no Brasil. Ocorre que a função extrafiscal do tributo verde interfere diretamente na economia, privilegiando um agente econômico em detrimento dos demais e gerando um conflito com o princípio da isonomia tributária do ponto de vista material. Além disso, a tributação verde não tem atingido os objetivos socioambientais a que se destina, de modo que a maior parte das isenções e concessões tributárias é realizada para atender a interesses políticos e econômicos, implicando na concorrência desleal e injusta.

Palavras-chave: Políticas tributárias. Tributação verde. Extrafiscalidade. Isonomia tributária. Livre concorrência.

\section{GREEN TAXATION AND THE POSSIBILITY OF VIOLATING DISTORTIONS OF THE PRINCIPLES OF ISONOMY AND FREE COMPETITION}

\begin{abstract}
The objective of the study was to discuss the possible violation of green taxation to the principles of equality and free competition in Brazil. It turns out that the extra-fiscal function of the green tax directly interferes in the economy privileging one economic agent over the
\end{abstract}

$1 \quad$ Mestranda em Direito Constitucional pela Universidade de Fortaleza (UNIFOR). Possui graduação em Direito pela Universidade de Fortaleza (2003), especialização em ESPECIALIZAÇÃO EM DIREITO E PROCESSO ADMINISTRATIVOS pela Universidade de Fortaleza (2006) e especialização em DIREITO PROCESSUAL: GRANDES TRANSFORMAÇÕES pela Universidade da Amazônia (2007). Atualmente é ADVOGADA da ORDEM DOS ADVOGADOS DO BRASIL. Endereço Postal: Rua Professor Heráclito, 990 Vicente Pinzon. Fortaleza - CE， CEP 60181-245 Email: emiliamota@globo.com. Lattes: http://lattes.cnpq.br/9755380044703003. Orcid: https://orcid.org/0000-0003-0489-3742

2 Doutorando em Direito Constitucional pela Universidade de Fortaleza (UNIFOR). Docente da Universidade de Fortaleza - UNIFOR. Coordenador geral da Escola de Direto da Pós-Graduação Lato sensu da UNIFOR. Especialização em Direito Empresarial pela Instituição FGV, em Direito e Processo Tributários (FIC) e em Auditoria (UFC). Mestre em Direito Constitucional - UNIFOR. Doutorando em Direito Constitucional UNIFOR. Docente da Escola Superior do Ministério Público e da Escola Superior de Advocacia. Docente integrante do Programa Tutorial Acadêmico do Centro de Ciências da Comunicação e Gestão da UNIFOR. Advogado. Consultor em Direito e Processo Tributário, atuando especialmente em desenvolvimento de projetos e programas relacionados à Auditoria jurídico-tributária. Endereço Postal: Av. Santos Dumont, 3131, sl. 1123. Aldeota. Fortaleza, CE, CEP: 60150-162. Email: elisberg@unifor.br. Lattes: http://lattes.cnpq.br/3994552193675752. Orcid: https://orcid.org/0000-0003-2927-3507 
others and generating a conflict with the principle of tax isonomy from a material point of view. In addition, green taxation has not achieved the socioenvironmental objectives for which it is intended, so that most tax exemptions and concessions are carried out to serve political and economic interests, resulting in unfair and unfair competition.

Keywords: Tax policies. Green Taxation. Extrafiscality. Tax isonomy. Free competition.

\section{INTRODUÇÃO}

A questão ecológica está relacionada a fatores como o processo de urbanização, o aumento da população, o desenvolvimento econômico e tecnológico, além das mudanças nos padrões de consumo. Esse conjunto de problemas relacionados ao meio ambiente levou a sociedade e o próprio Estado a repensarem sobre o tratamento dispensado à natureza.

Nas últimas décadas o desenvolvimento sustentável passou a ser tema de conferências internacionais e compromissos firmados entre os países, que se comprometeram a gerir os recursos ambientais de forma adequada (ROSSI; MARTINEZ; NOSSA, 2012). Por isso, no intuito de cumprir com os acordos firmados, o Brasil tem buscado desenvolver políticas públicas que aliem incentivos fiscais à preservação ambiental, como é o caso da chamada "tributação verde".

De acordo com Guedes Filho, Veronese e Klein (2017), a tributação verde representa um instrumento econômico cujo objetivo é incentivar o comportamento dos agentes para a promoção da melhoria do bem-estar e equidade social, além da redução dos riscos ambientais. Uma das principais características do tributo verde é o seu caráter extrafiscal, ou seja, ele é instituído com a intenção de mudar comportamentos e não necessariamente de aumentar a arrecadação.

O controle extrafiscal é um mecanismo comumente utilizado para estimular ou restringir comportamentos no sistema financeiro. A própria Constituição Federal de 1988, em seu art. 153, $\S 1^{\circ}$, institui a possibilidade de alteração da alíquota de determinados impostos, criando possibilidades para que o Estado intervenha no meio econômico pelo uso extrafiscal.

No entanto, a tributação extrafiscal nem sempre culmina com o resultado esperado, podendo gerar ainda mais desigualdade econômica e concorrencial. Isso acontece por que dentro do modelo fiscal adotado atualmente cada ente tem autonomia para instituir determinados tributos, podendo estabelecer vantagens fiscais a quem lhe prouver, alimentando a guerra fiscal e tornando a concorrência desleal (BOCAFOLI, 2012). 
Diante dessa possibilidade, questiona-se: quais os reflexos da tributação verde para a livre e justa concorrência entre as empresas no Brasil?

Para respondê-lo, o presente estudo teve como objetivo discutir a possível violação da tributação ambiental aos princípios da isonomia e livre concorrência no Brasil. O interesse na temática se justifica pelos impactos causados pela tributação na economia nacional, em especial na concorrência, que é um dos elementos formadores do preço de bens e serviços.

Além disso, acredita-se que o uso vantagens tributárias legítimas pode afetar o comportamento dos agentes econômicos no desenvolvimento de suas atividades, gerando outras repercussões no mercado que são de especial interesse para esta pesquisa.

Tratou-se de um estudo de abordagem exploratória. Os dados foram obtidos por meio de uma revisão da literatura utilizando livros e artigos jurídicos.

\section{TRIBUTAÇÃO AMBIENTAL: ASPECTOS GERAIS}

Antes de se debruçar sobre os aspectos da tributação ambiental no Brasil, faz-se necessário analisar o contexto global que ensejou a construção de uma legislação tributária que levasse em consideração os aspectos ambientais.

A preocupação com as questões ambientais é relativamente recente e ganhou força a partir da década de 1950 em países como Estados Unidos e França, em razão do aumento dos níveis de produção e consumo, além do processo de urbanização em que muitas pessoas migraram do campo para as cidades (PIMENTA, 2019). Esses fatores contribuíram para a ocorrência de desastres ecológicos, aumento dos níveis de poluição e aquecimento global.

$\mathrm{Na}$ década de 1970, segundo Montero (2014), começaram a surgir na Europa as primeiras denúncias contra empresas cujas atividades poluíam o meio ambiente, sendo que algumas delas foram investigadas e devidamente multadas pelo Estado. A partir de então alguns países europeus passaram a legislar sobre a temática, fazendo com que as empresas adotassem práticas responsáveis a exemplo da aquisição de equipamentos com menor volume de emissão de gases poluentes.

Com o passar do tempo, o movimento ambientalista se fortaleceu e conseguiu organizar grandes encontros e conferências internacionais em prol da causa, dentre as quais se destacam a Conferência de Estocolmo em 1972 e da ECO, em 1992, realizada no Rio de Janeiro, patrocinadas pela Organização das Nações Unidas (ONU) (PIMENTA, 2019). Outros 
encontros similares também foram organizados posteriormente por organizações como a OCDE e OMS.

No Brasil, a preocupação com a questão ambiental insere-se no contexto da Constituição Federal de 1988, como direito fundamental e garantia a ser protegida pelo Estado por meio de políticas públicas para proteção do meio ambiente. Faria (2014) explica que entre os instrumentos utilizados pelo Estado para garantir a preservação do meio ambiente está o tributo.

O Código Tributário Nacional traz o conceito de tributo em seu art. $3^{\circ}$, como sendo "toda a prestação pecuniária compulsória, em moeda ou cujo valor nela se possa exprimir, que não constitua sanção de ato ilícito, instituída em lei e cobrada mediante atividade administrativa plenamente vinculada" (BRASIL, 1966).

Em outras palavras, o tributo representa um valor pago ao Estado pelos contribuintes, que podem ser pessoas físicas ou jurídicas, no âmbito federal, estadual e municipal. Por meio dos recursos arrecadados, o Estado tenta cumprir suas funções em relação à sociedade nos mais diversos campos, inclusive na proteção ao meio ambiente.

Por sua vez, os tributos ambientais, também chamados de tributos verdes, consistem na utilização de uma política tributária para proteger o meio ambiente em todas as suas formas. De acordo com Faria (2014), trata-se de uma concepção jurídica voltada para vários objetivos, que perpassam pela geração de receitas, mas se estendem à orientação do comportamento do contribuinte.

A esse respeito, Silva (2012, p. 996) reforça que:

\begin{abstract}
Os tributos ambientais têm sua conceituação diretamente ligada à tutela do meio ambiente enquanto finalidade, sendo irrelevante a sua relação com o fato gerador , é dizer, um tributo ambiental não assume esta característica apenas pelo fato de prever sua incidência sobre um ato de degradação ambiental, mas sim pelo fato de ter uma finalidade conexa com a política de promoção ambiental.
\end{abstract}

Segundo Peralta (2015), os tributos ambientais são instituídos com objetivo de modificar o comportamento dos produtores e consumidores, ou seja, sua função primária é mudar comportamentos causadores de danos ambientais, sem a intenção de aumentar a arrecadação. No Brasil, esses tributos costumam ser nivelados conforme estimativas do custo do dano ambiental gerado e a mensuração dos objetivos a serem alcançados.

Outros autores, como Sebastião (2011), sugerem que para além da orientação ao comportamento do contribuinte, a tributação ambiental possui pelo menos outros dois 
objetivos: o atendimento ao princípio do poluidor-pagador (PPP) e a integração entre qualidade ambiental e eficiência econômica.

O PPP é um princípio que norteia o desenvolvimento de políticas públicas em matéria ambiental e que pode ser projetado sobre o sistema tributário, ensejando a criação de tributos ambientais. Montero (2014) avalia que a finalidade do PPP é fazer com que os custos sociais provocados por uma atividade que lese o meio ambiente repercutam nos custos finais dos produtos e serviços relacionados a ela.

Em outras palavras, o PPP atribui um caráter seletivo ao tributo ambiental que deverá incidir sobre atividade que impactem negativamente no meio ambiente. Nesse sentido, tanto o fato gerador quanto a graduação do tributo ambiental serão delimitados pelo PPP, observando critérios de proporcionalidade e equivalência, mas não de capacidade contributiva como ocorre com os demais tributos (PERALTA, 2015).

A integração entre a qualidade ambiental e a eficiência econômica é outro objetivo da tributação ambiental. De acordo com Sebastião (2011), a teoria do duplo dividendo, como também é chamada, consiste na possibilidade de o tributo ambiental obter ganhos colaterais de eficiência relacionados com a diminuição dos efeitos paralelos de outros tributos. Em outras palavras, os efeitos benéficos do tributo ambiental também auxiliam a diminuir as distorções tributárias decorrentes de outros tributos.

Ressalte-se que, apesar da existência de leis estaduais e municipais instituindo tributos ambientais, nota-se que a Constituição Federal não prevê nenhum tributo de natureza ambiental, ou seja, que tenha a degradação ambiental como fato gerador. Essa ausência fez com que o legislador utilizasse os tributos de forma indireta, utilizando-se da chamada “função extrafiscal dos tributos”, que é a principal característica do tributo verde.

\subsection{EXTRAFISCALIDADE}

O principal objetivo da instituição de um tributo é arrecadar os recursos para suprir as necessidades dos cofres públicos, referindo-se a sua finalidade fiscal. No entanto, o tributo também pode ser compreendido a partir de outras finalidades, como é o caso da extrafiscalidade, onde a arrecadação de valores para o Estado não é prioritária, mas busca intervir em dados estruturais da economia, alterando o comportamento do contribuinte.

A extrafiscalidade é um instrumento utilizado pelo Estado para alcançar as ações sociais desejadas e ordenar ou reordenar a economia. Segundo Mansano (2010, p. 106) “é um 
implemento na concessão de isenções, simplesmente objetivando recomendar ao cidadão uma ação ou omissão".

Folloni (2014) explica que a extrafiscalidade é uma estratégia empregada pelo Poder Público para conciliar o processo de desenvolvimento econômico com a defesa e preservação dos recursos naturais, o que atende a um dos objetivos da tributação ambiental. Em síntese, a extrafiscalidade é um mecanismo pelo qual o tributo deixa de representar apenas um angariador de receitas, passando a figurar como um elemento transformador da sociedade, tanto em matéria econômica, como política e ambiental.

Outros autores, como Silva (2012), acreditam que a tributação extrafiscal tem por objetivo a redistribuição de renda e de terras, a reorientação de investimentos em setores estratégicos de produção, a defesa da indústria nacional, desenvolvimento de ações educativas para reduzir as situações de risco e vulnerabilidade, como as desigualdades e vulnerabilidades sociais, além de contribuir para a conservação dos recursos naturais e preservação do meio ambiente.

De fato nota-se que existem duas vertentes relacionadas a extrafiscalidade na Constituição Federal: as normas voltadas ao desenvolvimento nacional e aquelas destinadas à realização da justiça social. Por isso, os tributos ambientais também podem ser classificados como tributos ambientais lato sensu ou tributos ambientais stricto sensu.

Os tributos ambientais lato sensu, ou de sentido impróprio, são tributos ordinários cuja finalidade primária é arrecadadora, mas que trazem em seus elementos algum efeito extrafiscal de caráter ecológico. Esse tipo de tributação compreende os incentivos que estimulam a preservação ambiental e os tributos que de forma indireta contemplam problemas ambientais, a exemplo da vinculação de receitas para fins ambientais (PERALTA, 2015).

Já os tributos ambientais stricto sensu, ou de sentido próprio, possuem caráter predominantemente extrafiscal. De acordo com Silva (2012), seu objetivo é orientar a conduta dos diversos agentes econômicos para que o impacto de suas atividades sobre o meio ambiente ocorra de maneira sustentável. Este tipo de tributo ainda é escasso no Brasil.

Nessa linha de raciocínio, Peralta $(2015$, p. 14) ressalta que:

O que permite qualificar um tributo como ambiental stricto sensu é a sua estrutura e não a finalidade declarada na norma. De maneira que, um tributo cuja única nota ambiental se afinque no destino das receitas obtidas não apresenta nenhum tipo de especialidade desde a perspectiva do direito tributário. 
Dentre os principais exemplos de tributos verdes instituídos no Brasil é possível citar o ICMS ecológico. Conforme as disposições constitucionais, $75 \%$ da arrecadação do Imposto sobre Circulação de Mercadorias e Serviços é receita do Estado, sendo que os $25 \%$ restantes pertencem aos municípios. A ideia do ICMS ecológico consiste no repasse de uma cota-parte do valor que cabe aos municípios, aqueles que possuem unidades de conservação ambiental voltadas a preservação do meio ambiente em seus territórios (ROSSI; MARTINEZ; NOSSA, 2012).

De acordo com Faria (2014), alguns estados brasileiros vêm desenvolvendo atividades nesse sentido, entre eles o Estado de São Paulo, Mato Grosso, Rio Grande do Sul e Amapá. Outros estados, como Bahia, Goiás e Ceará estão em fase de debates ou com projetos em fase de tramitação.

Outro exemplo de tributo ambiental instituído em vários municípios brasileiros é o IPTU verde. O Imposto Predial Territorial Urbano encontra previsão legal no art. 156, inciso I, da Constituição Federal de 1988, sendo de competência administração municipal (BRASIL, 1988). Recentemente surgiram projetos de leis municipais versando sobre a possibilidade de redução da alíquota de IPTU quando forem constatadas práticas sustentáveis e benéficas ao meio ambiente.

Passos e Rangel (2016) explicam que o IPTU verde é uma política pública que autoriza a concessão de descontos ou isenção fiscal para contribuintes que auxiliem o Poder Público na promoção de práticas sustentáveis, incentivando ações como preservação de áreas verdes, reutilização da água da chuva, coleta seletiva, captação de energia solar, dentre outras atividades.

Alguns dos projetos de descontos por meio de IPTU verde já integram leis municipais como nos municípios de Curitiba/PR (Lei nº. 9.806/00), Sorocaba/SP (Lei $n^{\circ}$. 9.571/11) e Guarulhos/SP (Lei no. 6.793/10), onde os descontos podem chegar ao patamar de $25 \%$ no valor do IPTU anual.

Apesar das vantagens trazidas pela tributação ambiental, como a diminuição dos níveis de emissão de gases poluentes, redução do desmatamento e adoção de comportamentos não poluidores, a literatura aponta que o tributo extrafiscal pode conduzir a uma configuração estranha à igualitária da carga tributária, chocando-se com outros princípios.

\section{A FUNÇÃO EXTRAFISCAL E O PRINCÍPIO DA IGUALDADE TRIBUTÁRIA}


Em termos jurídicos, a palavra princípio normalmente é empregada para designar normas que possuem status diferenciado em relação às demais e que fixam valores ou critérios priorizados na aplicação em todo o sistema normativo (BOCAFOLI, 2012). Em outras palavras, os princípios representam diretrizes fundamentais para a elaboração das demais normas, imprimindo-lhes um caráter de unidade relativa.

Nesse sentido, o princípio da igualdade ou isonomia é um dos postulados que se superpõe em relação às demais normas, situando-se no campo das chamadas metanormas, caracterizadas por impor um dever de segundo grau.

A igualdade representa um dos pilares das constituições modernas, inclusive da Constituição Federal de 1988, que em seu art. 5, caput, estabelece que "todos são iguais perante a lei (...)" (BRASIL, 1988). No entanto, alguns autores entendem que a igualdade positiva, em seu sentido formal, não se satisfaz. Pelo contrário, o tratamento igualitário perante a lei apresenta-se com uma justificativa perfeita para o efetivo tratamento não isonômico (LONDE; GUEDES, 2015).

Esse entendimento é compartilhado por Canotilho (2007, p. 563), cuja obra inspirou a $\mathrm{CF} / 88$, ao admitir que "ser igual perante a lei não significa apenas aplicação igual da lei. A lei, ela própria, deve tratar por igual todos os cidadãos. O princípio da igualdade dirige-se ao próprio legislador, vinculando-o à criação de um direito igual para todos os cidadãos”.

Na realidade, a igualdade de que trata a $\mathrm{CF} / 88$ pode ser analisada sob duas vertentes: a igualdade perante a lei, ou seja, igualdade formal, que garante que todos estejam submetidos às normas legais e a igualdade material, que garante que as leis tratem igualmente aqueles que estão em situações iguais (BOCAFOLI, 2012).

De acordo com Peralta (2015), para que o princípio da igualdade seja respeitado, não raramente o Poder Legislativo institui regras gerais, fixando determinados padrões, já que é impossível prever todas as situações que podem ocorrer. Mas o Legislativo também costuma estabelecer dispositivos que possam minimizar eventuais discrepâncias entre a norma e a situação de fato, permitindo que a lei seja aplicada conforme cada caso, a exemplo do que ocorre no campo tributário.

Há diversos preceitos constitucionais impregnados pelo princípio da isonomia no campo tributário, a exemplo do art. 151 da $\mathrm{CF} / 88$, que veda a tributação não uniforme em todo o território nacional ou tributação que implique em distinção ou preferência em relação aos entes públicos, com exceção de incentivos fiscais destinados à promoção do equilíbrio socioeconômico (BRASIL, 1988). 
Ocorre que alguns desses incentivos fiscais acabam resultando no tratamento desigual dos contribuintes, a despeito do que ocorre com alguns tributos extrafiscais. Parte da doutrina adota uma postura de tomar a igualdade tributária como um princípio jurídico que pode ser realizado por meio de critérios discriminatórios diferentes, atendendo à chamada igualdade material. Nesse caso, o critério da capacidade contributiva, por exemplo, poderia ser flexibilizado diante de uma norma tributária extrafiscal (GODOI, 2014).

Segundo Peralta (2015), o aspecto econômico da isonomia tributária se manifesta por meio da capacidade contributiva. Para o autor, é o princípio da isonomia tributária que permite ao Estado diferenciar as pessoas e estabelecer quais indivíduos ou categorias seriam desiguais e a medida dessas desigualdades, citando o exemplo dos incentivos fiscais destinados à promoção do equilíbrio e desenvolvimento econômico, previsto no art. 151 da $\mathrm{CF} / 88$.

Para Godoi (2014) a tributação extrafiscal, cujo objetivo difere da arrecadação, seria consequência direta da supremacia do interesse público sobre o interesse do particular, o que implicaria a possibilidade de afastamento da isonomia para sua aplicação. Em outras palavras, seria possível afirmar que o tributo extrafiscal, como o tributo verde, não precisaria obedecer ao princípio da igualdade tributária.

A esse respeito, Bocafoli (2012, p. 22) entende que:

No que concerne especificamente ao princípio da igualdade, expressamente previsto no âmbito tributário, o que se observa é que a extrafiscalidade nem sempre implica o seu necessário desprestígio. Muito pelo contrário, ela pode revelar-se justamente pela aplicação estrita de referido princípio, sobretudo, ao dar efetividade à segunda sentença da clássica definição de igualdade (tratamento desigual para os desiguais na medida em que se desigualam).

Assim, diante da aplicação de uma espécie tributária extrafiscal, o critério da capacidade contributiva do agente seria descartado, dando lugar aos critérios de discriminação que estejam relacionados com a finalidade da obra. É o que ocorre, por exemplo, com o ICMS verde, onde a capacidade contributiva da empresa encontra-se em segundo plano, já que a finalidade da norma é garantir a preservação ambiental.

No entanto, há uma corrente divergente. De acordo com Silva (2009), a capacidade contributiva é um dos princípios gerais do Direito Tributário brasileiro, relacionando-se inclusive com o âmbito extrafiscal. A autora sugere que a capacidade contributiva é um fator 
de limitação para a tributação extrafiscal e protege o mínimo existencial da tributação com base na extrafiscalidade, vedando o confisco:

\footnotetext{
O princípio da isonomia tributária deve ser operacionalizado através do princípio da capacidade contributiva. A capacidade contributiva e os princípios da Ordem Econômica poderão compreender-se numa relação de integração, já que ambos servem para atingir a mesma finalidade preconizada na Constituição, consubstanciada nos princípios da justiça e da solidariedade (SILVA, 2009, p. 236).
}

Nesse sentido, a capacidade contributiva também deveria ser levada em consideração no que diz respeito aos tributos extrafiscais, não para graduar o tributo de acordo com a capacidade contributiva do agente, mas para definir os parâmetros de tributação e garantir a indução do comportamento.

Para Folloni (2014), se o objetivo da tributação extrafiscal é estimular ou desestimular determinada conduta, ela diferenciará os contribuintes, separando-os em classes: em uma delas permanecem os agentes que não realizam determinada conduta e que não serão diretamente afetados pela tributação. Na outra, ficam os que realizam a conduta e que gozarão dos efeitos estimulantes da regra tributária.

O autor cita um exemplo em que se aumenta a tributação sobre a produção industrial de contribuintes que não implementam meios adequados de tratamento de resíduos da produção, com a finalidade de estimular a adoção desses meios. Essa tributação diferenciaria os contribuintes em duas classes: aqueles que já possuem os meios, e que não sofrerão os efeitos tributários extrafiscais e aqueles que não os têm e sofrerão os efeitos da tributação extrafiscal (FOLLONI, 2014).

A partir do exemplo citado, pode-se afirmar que entre aqueles contribuintes inseridos na classe dos destinatários da tributação extrafiscal, compartilhando o mesmo ônus tributário destinado a provocar condutas omissivas ou comissivas, a capacidade contributiva é o principal fator a ser levado em consideração, evitando-se que as diferenças de capacidade econômica gerem desigualdades e consequentemente a ineficiência da extrafiscalidade.

Em outras palavras, se a capacidade contributiva do agente não for levada em consideração, os efeitos da tributação extrafiscal serão desiguais, ou seja, os contribuintes com capacidade econômica elevada serão submetidos à tributação com efeitos semelhantes daqueles contribuintes de menor capacidade econômica. Essa diferenciação não encontra respaldo no princípio da isonomia, mesmo quando observado do ponto de vista da igualdade material. 
Folloni (2014) argumenta no sentido de que a igualdade é um direito constitucional axiológico e que a sua restrição envolve, obrigatoriamente, razões de relevância ímpar. Por isso, a tributação extrafiscal não pode ser usada á toa, mas apenas para a promoção dos fins mais elevados, como é o caso dos fins socioambientais, desde que observada a capacidade contributiva dos envolvidos, o que não ocorre na prática.

Outros autores, como Vidigal (2015), corroboram com esse entendimento e reiteram que a maioria dos métodos extrafiscais de intervenção na atividade econômica não têm respeitado os objetivos econômicos e sociais a que se propõem, citando o exemplo das concessões realizadas com interesses políticos ou realizadas de forma arbitrária, que acarretam não apenas no tratamento desigual àqueles iguais, como também na prática de concorrência desleal entre as empresas.

\section{REFLEXOS DA TRIBUTAÇÃO AMBIENTAL SOBRE A LIVRE E JUSTA CONCORRÊNCIA}

Ao tratar da ordem econômica e financeira, a Constituição Federal de 1988 filiou-se ao sistema caracterizado pelas leis de mercado, pela livre iniciativa e livre concorrência, conforme se extrai da redação de seu art. 170, inciso IV. Além disso, em seu art. 173, a Carta Magna Federal prevê a repressão do abuso do poder econômico que objetive a dominação dos mercados e a eliminação da concorrência (BRASIL, 1988).

De acordo com Caliendo (2011), o principal objetivo da ordem econômica é assegurar a todos uma existência digna, observando os ditames da justiça social e os princípios de soberania nacional, função social da propriedade, propriedade privada, livre concorrência, defesa do consumidor, redução das desigualdades regionais, dentre outros aspectos.

A livre concorrência é uma garantia de que as atividades econômicas serão desenvolvidas de maneira que as habilidades de cada agente sejam os únicos fatores determinantes para seu sucesso ou insucesso, não devendo o Estado favorecer ou desfavorecer qualquer agente econômico (RIBEIRO, 2014). Trata-se da garantia de oportunidades iguais para todos os agentes, uma forma de desconcentração de poder.

Por outro lado, Gonçalves e Bonat (2018) ressaltam que em um Estado Democrático de Direito, a livre concorrência não pode ser considerada de forma absoluta, devendo os agentes econômicos nortear tal liberdade em consonância com outros valores e princípios 
constitucionais. Dessa forma, a livre concorrência não poderá ser considerada nos casos em que lese os interesses dos consumidores, de outros concorrentes e do meio ambiente, por exemplo.

Buchain (2014) corrobora com esse entendimento ao afirmar que:

\begin{abstract}
A política da concorrência tem como objetivo exclusivo maximizar a eficiência econômica. Segundo essa visão, as políticas públicas da administração para a concorrência não admitem a escolha de objetivos sócio-políticos tais como a diminuição das desigualdades regionais e outros que foram designados na Carta brasileira, rejeitando-os como ínsitos à política da concorrência porquanto dependem de juízo de valor subjetivo e, por isso mesmo, impossíveis de serem consistentemente aplicados ao direito da concorrência. (BUCHAIN, 2014, p. 6)
\end{abstract}

Para Caliendo (2011), o objetivo do princípio da livre concorrência não é apenas alcançar um estado de equilíbrio em relação à eficiência econômica, mas servir como instrumento para alcance de outros valores, como a justiça social e a livre iniciativa. Dessa forma, o papel do Estado é retributivo, devendo garantir a igualdade de condições nas relações econômicas e coibir qualquer tentativa de dominação do mercado por qualquer que seja o agente econômico.

Na realidade, a livre concorrência incorpora outros valores como a função social da propriedade, a repressão ao abuso de poder econômico e o bem-estar do consumidor. Esse princípio somente é aplicável dentro de um sistema de economia de mercado, tendo em vista que o seu objetivo é garantir a manutenção da relação de equilíbrio entre oferta e procura, garantindo a liberdade dos agentes no mercado, sem a interferência do Estado.

Por outro lado, vale lembrar que a adoção da economia de mercado e a adoção da livre concorrência não conflitam com a possibilidade de intervenção do Estado na economia. Pelo contrário, estes fatores se complementam, levando em conta que o Estado permite que as empresas atuem livremente no mercado, mas age quando precisa salvaguardar seus princípios e os interesses individuais ou coletivos que deles decorrem (RIBEIRO, 2014).

Lima (2012) sustenta que a livre concorrência também deve ser um dos princípios norteadores da relação entre o Sistema Tributário Nacional e a Ordem Econômica Financeira. De fato, a importância da tributação para garantir a livre concorrência encontra respaldo na própria $\mathrm{CF} / 88$, que em seu art. 146-A, assim dispõe: “A Lei complementar poderá estabelecer critérios especiais de tributação, com o objetivo de prevenir desequilíbrios da concorrência, sem prejuízo da competência de a União, por lei, estabelecer normas de igual objetivo". 
Tal redação evidencia a preocupação do legislador para que tributação não afete a livre concorrência. A exação dos tributos é essencial para todos os agentes do mercado, inclusive para o próprio Estado, podendo alterar a dinâmica do mercado, a exemplo do que ocorreu recentemente quando o Governo Federal anunciou a redução do Imposto sobre Produtos Industrializado (IPI) incidente sobre veículos e eletrodomésticos (GONÇALVES; BONAT, 2018).

No entanto, entende-se que sempre que o Estado interferir para privilegiar ou prejudicar alguns ou vários agentes econômicos, independente de qual seja a sua real intenção, esta ação impactará positiva ou negativamente para outros agentes. Assim, apesar da expressão "livre concorrência" parecer pressupor uma neutralidade tributária do Estado, na prática, não é o que se observa.

De acordo com Silva (2009), sempre que a política tributária não estiver harmonizada com os demais objetivos da política econômica, ocorreram desequilíbrios concorrenciais. Para ilustrar tal entendimento, a autora cita o caso da instalação da multinacional Ford Motor do Brasil no Rio Grande do Sul no início da década de 2000, cujos valores, apenas no que diz respeito à doação de terrenos públicos e concessão de isenção de ICMS, giraram em torno de R \$ 3 bilhões, sem contar com os demais investimentos e concessões públicas.

Segundo a mesma autora, à época da isenção fiscal cedida pelo Estado a empresa era a terceira maior do mundo, ou seja, não necessitava de qualquer incentivo fiscal para instalar sua sede na região. Ademais, a autora ainda cita que outras empresas buscaram incentivos públicos para instalação na mesma região anteriormente, mas estes incentivos foram negados pela Administração, o que leva a crer no favorecimento do agente econômico em questão (SILVA, 2009).

A concessão de isenções ou benefícios fiscais em razão da tributação ambiental também pode incorrer em desequilíbrios concorrenciais, levando em conta que a intervenção estatal por meio da extrafiscalidade pode privilegiar um agente econômico em detrimento dos demais. Lima (2012) cita o exemplo das políticas ambientais de isenção municipal ou estadual que normalmente resultam em vantagens territoriais. No entanto, a problemática se reflete em outras dimensões.

Ocorre que mesmo com a crescente utilização da tributação para fins de proteção ambiental, o que em tese tornaria os tributos verdes econômico e ambientalmente viáveis, 
estes instrumentos não tem contribuído para a efetivação do seu objetivo maior, suscitando dúvidas sobre sua eficácia na tutela dos recursos ambientais (OLIVEIRA NETTO, 2014).

De acordo com Silva (2012), a tributação ambiental acaba afetando negativamente os rendimentos privados, além de provocar reduções no Produto Interno Bruto (PIB) e no padrão de consumo e bem-estar das pessoas. Além disso, em vez de reduzirem, acabam aumentando as distorções no mercado, notadamente no que diz respeito ao âmbito concorrencial, com raríssimas exceções.

Segundo Folloni (2014), os danos concorrenciais poderão ocorrer nos casos em que os agentes utilizarem as vantagens tributárias promovidas pela tributação verde para a formação de preços e melhoria na qualidade dos seus bens e serviços, sendo que esses comportamentos podem resultar em barreiras mercadológicas e dificultar a criação, funcionamento ou desenvolvimento de empresas concorrentes, o que vem acontecendo costumeiramente no caso brasileiro.

Nota-se que a ideia de eficiência econômica e de neutralidade fiscal que o Estado almeja através da instituição de tributação distorcida não se compatibiliza coma a finalidade primária dos tributos, ou seja, a finalidade fiscal. Mesmo no caso dos tributos extrafiscais, como é o caso do tributo verde, o anseio do Estado pelo aumento da receita se sobressai e limita o discurso extrafiscal à teoria e à aceitação social, enquanto na prática o Estado obtém vantagens fiscais ou não raramente escusas (SILVA, 2012).

Ressalte-se que não se trata de negar eventuais efeitos positivos da tributação ambiental na perspectiva da sustentabilidade e preservação dos recursos naturais, mesmo por que, em alguns casos, esse objetivo é concretizado. No entanto, o que se observa é um desvio de finalidade da norma em relação à livre e justa concorrência entre as empresas, principalmente no que diz respeito àquelas de menor porte que não conseguem competir com as maiores.

Sobre a instituição dos tributos verdes, Silva (2012, p. 1020) argumenta que:

As pressões de grupos econômicos e o anseio político por receita ainda parecem ser a melhor explicação para a criação destes instrumentos, fato que compromete sua eficácia enquanto meio de proteção dos recursos naturais. Em tempos em que a proteção do meio ambiente ganha cada vez mais destaque, a finalidade arrecadatória do Estado, velha conhecida dos contribuintes, ressurge "socialmente correta", mas agora vestida de verde. 
Para autores como Ribeiro (2014) a instituição dos tributos ambientais ou tributos verdes constitui-se em uma prerrogativa do Estado para alterar o comportamento de agentes poluidores e garantir que a atividade econômica transcorra de maneira sustentável. No entanto, segundo o autor, o Estado precisaria repensar os limites da concorrência fiscal ao instituir tais tributos, evitando proporções negativas para a atividade econômica e atividade das empresas.

Mesmo os defensores dos incentivos fiscais promovidos a partir da tributação ambiental reconhecem a necessidade de limitar esse tipo de iniciativa, principalmente no que diz respeito à capacidade contributiva do agente econômico. Nesse sentido, Rodrigues (2013) sustenta que somente quando a capacidade contributiva do agente for observada, a tributação verde poderá garantir a sustentabilidade ambiental e de mercado.

Ressalte-se ainda nem todo incentivo fiscal promovido pelo Estado implica diretamente no desequilíbrio da concorrência ou violação do princípio da igualdade, mas aquele que viola a neutralidade concorrencial do tributo, levando-se em consideração que o tratamento tributário diferencial entre concorrentes não encontra respaldo na Constituição. É o caso, por exemplo, de empresas que se instalam em regiões desenvolvidas e cujos custos para aquisição de insumos são iguais aqueles de seus concorrentes instalados e regiões menos desenvolvidas (VIDIGAL, 2015).

Oliveira Netto (2014) afirma que embora a tributação ambiental represente um método extrafiscal de intervenção estatal na atividade econômica, a iniciativa não tem respeitado seus objetivos econômicos e sociais, o que já era previsto desde que tais medidas começaram a ser implantadas. $\mathrm{O}$ autor sustenta que concessões estritamente políticas ou arbitrárias ainda marcam o cenário empresarial no Brasil, fortalecendo a prática de concorrência desleal entre as empresas.

Outro fator citado por Vidigal (2015) é que a tributação ambiental não raramente tem como finalidade favorecer o desenvolvimento regional, mas acaba incidindo sobre atividades desenvolvidas por empresas estrangeiras. O autor corrobora com o entendimento supracitado e sugere que a proteção ao bem comum e a justiça social baseada na igualdade de condições de mercado não tem sido verificados nas concessões de incentivos fiscais promovidos por estados e municípios, de modo que os índices de concorrência desleal continuam amplos.

Segundo Oliveira Netto (2014) a solução para a situação passaria por um mecanismo de limitação da tributação ambiental ou até mesmo pela fiscalização, de modo que uma empresa somente poderia receber qualquer tipo de estímulo fiscal ambiental se estivesse de 
fato contribuindo com a preservação do meio ambiente, ou seja, um tributo verde, como o ICMS verde, por exemplo, somente poderia ser concedido após o início das atividades da empresa em uma região e não antes, como vem ocorrendo sumariamente.

Assim, acredita-se que o Estado enquanto garantidor da ordem econômica deve agir para evitar possíveis desníveis concorrenciais decorrentes da tributação ambiental, além de promover a livre concorrência por meio de outros instrumentos legalmente previstos. Cumpre à atividade tributária o pleno exercício da livre concorrência, um dos pilares de sustentação do Estado Democrático de Direito.

\section{CONSIDERAÇÕES FINAIS}

O principal objetivo das espécies tributárias previstas no sistema consiste na arrecadação, ou seja, no abastecimento dos cofres públicos para que o Estado consiga desenvolver suas atividades e comandos constitucionais atrelados a diversos setores. Mas, os tributos também podem ser utilizados com finalidades distintas da arrecadação, a exemplo da regulação do comportamento dos indivíduos, atividade esta conhecida como função extrajudicial.

Dentre os tributos com função extrafiscal destacam-se os chamados tributos ambientais, também conhecidos como tributos verdes. A literatura aponta que os tributos verdes assim são chamados em virtude da sua relação com o Direito Ambiental, na medida em que são instituídos, em tese, visando à preservação dos recursos naturais e sustentabilidade da atividade econômica, a exemplo do ICMS e do IPI verdes.

Por outro lado, mesmo diante da função extrafiscal de tais tributos, que consiste na tentativa de alterar o comportamento dos agentes econômicos, sustenta-se que não poderia o legislador deixar de observar os limites ao poder de tributar fundamentos pelo Sistema Tributário, principalmente no que concerne aos princípios da isonomia tributária e livre e justa concorrência.

O que se observa é que há casos em que a extrafiscalidade da tributação ambiental manifesta-se em desprestígio da isonomia entre os agentes econômicos, principalmente em se tratando da não observância da capacidade contributiva destes agentes quando da concessão de incentivos e isenções fiscais na seara ambiental. A literatura aponta a função extrafiscal do tributo verde interfere diretamente na economia e acaba privilegiando um agente econômico 
em detrimento dos demais, o que vai a desencontro com a ideia isonomia, mesmo que do ponto de vista material.

Essas alterações nas condições de mercado também impactam diretamente sobre a livre concorrência, um dos princípios basilares da economia e que em última análise decorre da própria isonomia tributária. Ocorre que a tributação verde não tem atingido os objetivos socioambientais a que se destina, de modo que a maior parte das isenções e concessões tributárias é realizada para atender outros interesses políticos e econômicos, acarretando tratamento desigual entre os agentes e implicando diretamente na concorrência desleal e injusta.

Não há dúvida sobre a importância de incentivar o cuidado com o meio ambiente para que a vida no planeta possa continuar existindo e que ações voltadas à preservação dos recursos naturais e sustentabilidade devem ser incentivadas. No entanto, as políticas públicas também devem prestigiar o direito a um ambiente econômico saudável, que abrange a livre concorrência entre os agentes econômicos sem a interferência do Estado, principalmente quando tal interferência está fundada em interesses puramente políticos.

Acredita-se que o desenvolvimento sustentável somente é possível com o equilíbrio entre a proteção ao meio ambiente e os avanços econômicos. Nesse sentido, qualquer política tributária deve ser objeto de uma análise rigorosa em relação aos seus efeitos direitos e indiretos, evitando que a extrafiscalidade tributária ameace o equilíbrio das relações econômicas.

\section{REFERÊNCIAS}

BOCAFOLI, A. I. Extrafiscalidade e princípio da igualdade tributária: compatibilidade e confronto com os limites do poder de tributar. Revista FMU Direito, v. 26, n. 38, p. 15-24, 2012.

BRASIL. Constituição Federal. Constituição da República Federativa do Brasil. Brasília: Senado Federal, 1988.

Lei Complementar no $\mathbf{n}^{\circ} 172$ de 25 de outubro de 1966. Dispõe sobre o Sistema Tributário Nacional e institui normas gerais de Direito Tributário aplicáveis à União, Estados e Municípios. Brasília: Casa Civil, 1966.

BUCHAIN, L. C. Os objetivos do Direito da Concorrência em face da ordem econômica nacional. Cadernos do Programa de Pós-Graduação em Direito da UFRGS, v. 9. n. 1, p. 1-26, 2014. 
CALIENDO, P. Princípio da livre concorrência em matéria tributária-conceito e aplicação. Direito Tributário em questão, v. 3, n. 7, p. 115-132, 2011.

CANOTILHO, J. J. G. Direito Constitucional e Teoria da Constituição. 7. ed. São Paulo: Almedina Brasil, 2007.

FARIA, A. L. S. Tributo verde: o IPTU e a tributação indutora como instrumento para o desenvolvimento sustentável. Curitiba: Appris, 2014.

FOLLONI, A. Isonomia na tributação extrafiscal. Revista Direito GV, São Paulo, v. 10, n. 1, p. 201-220, 2014.

GUEDES FILHO, Ernesto Moreira; VERONESE, Helena; KLEIN, Fábio. A IMPLANTAÇÃO DE SISTEMAS DE INCENTIVO TRIBUTÁRIOS PARA REDUÇÃO DE IMPACTOS AMBIENTAIS (“TRIBUTO VERDE”) NA ECONOMIA BRASILEIRA. In: Transição para uma nova ética tributária: a sustentabilidade como objetivo econômico. CASTRO, Renault de Freitas. (org.). Brasília: Ler, 2017

GODOI, M. S. A alíquota agravada de contribuição social sobre os lucros das instituições financeiras (art. 17 da Lei 11.727/2008). In: ROCHA, V. O (Coord.). Grandes questões atuais de Direito Tributário. v. 18. São Paulo: Dialética, 2014.

GONÇALVES, O. O; BONAT, A. L. Análise econômica do Direito, incentivos fiscais e redução das desigualdades regionais. Revista Jurídica da Presidência, v. 20, n. 121, p. 381407, 2018.

LIMA, S. N. C. A extrafiscalidade à luz do sistema constitucional brasileiro. Boletim Científico ESMPU, Brasília, v. 11, n. 39, p. 215-236, 2012.

LONDE, C. R. O; GUEDES, F. A. Eventuais efeitos sancionatórios da extrafiscalidade e sua (in) adequação ao ordenamento jurídico brasileiro. Revista de Direito Tributário e Financeiro, v. 1, n. 2, p. 539-562, 2015.

MANSANO, J. A tributação ambiental como instrumento de desenvolvimento econômico sustentável. Revista Espaço Acadêmico, n. 114, p. 100-109, 2010.

MONTERO, C. E. P. Tributação ambiental: reflexões sobre a introdução da variável ambiental no sistema tributário. São Paulo: Saraiva, 2014.

OLIVEIRA NETTO, A. Compatibilidade de um tributo ambiental com o Sistema Tributário Nacional. 2014. Dissertação apresentada ao Programa de Pós-Graduação em Direito Econômico, Financeiro e Tributário da Faculdade de Direito da Universidade de São Paulo, São Paulo, 2014.

PASSOS, R. S; RANGEL, S. Modelo de gestão para o IPTU verde como indutor do desenvolvimento sustentável nos municípios. REA, v. 15, n. 2, p. 234-252, 2016. 
PERALTA, C. E. Tributação ambiental no Brasil: reflexões para esverdear o sistema tributário brasileiro. Revista de Finanças Públicas, Tributação e Desenvolvimento RFPTD, v. 3, n. 3, p. 1-28, 2015.

PIMENTA, P. R. L. Direito Tributário Ambiental. Rio de Janeiro: Forense, 2019.

RIBEIRO, M. F. Tributação e concorrência: breve análise sobre a aplicabilidade do art. 146 da Constituição Federal. Derecho y Cambio Social, v. 40, n. 6, p. 1-28, 2014.

RODRIGUES, P. R. Tributação ambiental: a intervenção do Estado no domínio econômico e a livre iniciativa. Revista de Direitos Sociais e Políticas Públicas, v. 1, n. 1, p. 119-143, 2013.

ROSSI, Aldimar; MARTINEZ, Antonio Lopo; NOSSA, Valcemiro. ICMS ECOLÓGICO SOB O ENFOQUE DA TRIBUTAÇÃO VERDE COMO MEIO DA SUSTENTABILIDADE ECONÔMICA E ECOLÓGICA: experiência do Paraná. Revista de Gestão Social e Ambiental, [S.L.], v. 5, n. 3, p. 90-101, 22 mar. 2012.

SEBASTIÃO, S. M. Tributo ambiental: extrafiscalidade e função promocional do Direito. 1. ed. Curitiba: Manole, 2011.

SILVA, D. A. Tributos verdes: proteção ambiental ou uma nova roupagem para antigas finalidades? Revista do Instituto do Direito Brasileiro - RIDB, v. 1, n. 8, p. 993-1023, 2012.

SILVA, L. R. F. Extrafiscalidade, incentivos fiscais: ausência de igualdade e justiça no desenvolvimento regional. Revista Argumentum, n. 10, p. 227-244, 2009.

VIDIGAL, C. L. Poder de tributar: seus efeitos sobre a concorrência. 2015. Dissertação apresentada ao Programa de Pós-Graduação em Direito Econômico, Financeiro e Tributário da Faculdade de Direito da Universidade de São Paulo, São Paulo, 2015. 